\title{
Conflicted Rules Theory (CRT) A New Arab Theory in Sociology ${ }^{(*)}$
}

\section{Dr. Ahmed Mousa Badawi ${ }^{(* *)}$}

This theory belongs to the structure-agency approach. It is a result of the limited attempts in researches and studies I undertook since 2004, (Badawi: 2004, 2009a, 2009, 2013,2014 ) and which continued until the pillars of this theory in question have been laid down. I think that this theory offers a new approach which is different from those of the main theorists in this field Pierre Bourdieu, (1977, 1993, 1994, 1997) Anthony Giddens, (1984, 1987, 2005) Margaret Archer, $(1995,2000)$. I have benefited from the theoretical heritage of contemporary sociology, such as Randall Collins's theories of conflict $(1975,1979)$, Sheldon Stryker's theories of interaction, especially the Symbolic Constructivism, $(1980,1987)$ Jeffrey C. Alexander's Neo functionalism, (1988, 1989) and Ulrich Beck's Cosmopolitanism. (1989, 2012, 2014, 2016).

I also assume that (CRT) offers clear and analogical concepts instead of these ambiguous relations and concepts that are common in many western sociology theories. Furthermore, it can be developed and its interpretation can be extended in different branches of

(*) This article was translated to English by: Mahmoud Nagah Khalaf and Ahmad Muhammad Hamza

(**) Freelance Sociological Researcher-Egypt.

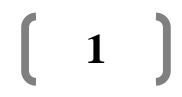


Nile Valley Journal of Human studies and social research

(ISSN : 2536 - 9555)

Sociology. In addition, it can be used to develop interresearch in social sciences

This theory in question has many ideas in common with Bourdieu's, Giddens's and Archer's theories, yet there is a number of essential points which distinguish it from them, as follows: (1) Bourdieu's theory managed to extensively elaborate on interpretation of the processes of reproduction, yet it is unable to explain the social change; (2) the ambiguity of the duality of structure concept in the Structuration Theory and its inability to unveil the impact of the cultural factors in making change; and (3) even though Margaret Archer discovered the weakness points in Giddens's theory, she largely relied on the cultural factors in analyzing it and ignored meanwhile the factors of power and hegemony that deeply influence social structure.

The main concepts of (CRT) include: agency, structure, structural rule, the five social realms, the privacy of the social realm, conflict and integration. Within these lines, I will offer brief definition for each of these items after which I shall extensively elaborate on them:

(1) Social agency: it comes before the structure and it is the origin of the structural rule. We define it as a personal motivation for the realization of a dynamic, intellectual or spiritual purpose, embodied in the practice of interactions and social relations, and formed through the surrounding physical, social and spiritual environment of the agent. Social agency is often organized into the routine of everyday life in the form of closely related actions that have acquired a pre-existing pattern. Sometimes its purposes (dynamic, intellectual or spiritual) 
Nile Valley Journal of Human studies and social research

are achieved in a new way because of one or more factors of change.

(2) the structural rules: abstracted actions free from time and space, has a linguistic, value and standard connotation, evoked by the agent to organize the motives and achieve the dynamic, intellectual or spiritual purposes. Some individuals abide by the rules voluntarily and ethically because of social socialization, while others are bound by a compulsory legal obligation because of the penalty authority (reward or punishment) imposed by the group or society.

(3) the Three-fold social structure: abstract rules to manage the social life; it is composed of three substructures: common interactive structure which is based on oral interaction rules, Institutional structure that is based on the bureaucratic rational rules, and the dark tunnel structure which is based on counter-rules of interactive and institutional rules.

(4) the social realms: man, in this age of globalization, lives in five interactive social realms, ranging from simplicity to structure and complexity. Each of these realms represents an independent social fact (social structure, demographic characteristics, pattern and production relations, spiritual and intellectual system).We divide it into two main groups: the first is called IN Realms which consist of: small social realm (Micro), communities and institutions realm (Meso), the big society (Macro). The second group is called Out Realms, which includes the (Reign Society) and the (Global Society). 
Nile Valley Journal of Human studies and social research

(ISSN : 2536 - 9555)

(5) privacy of the social realm: Every social realm has its own privacy, where each of them has a different relationship among its three sub-structures. And because a pattern of structural rules has historically accumulated content, It has relative importance and varying strength for each rule within the social structure.

\section{1- Hypotheses of the (CRT)}

The first hypothesis: each of the five social realms had the ability to automatically change the system of rules because of the structural ability of the new individual, collective or authoritarian agencies. The effect of change may extend to the other social realms because of the interaction and overlap relations that connect the five realms.

The second hypothesis: the Three-fold social structure rules are in semi-permanent conflict with each other and with their counterparts in the other realms because of the historical privacy of the compound social structure in each social realm, taking into account that there are partial integration or existence patterns that connect these structures together.

The third hypothesis: the out-realms (reign and global) effective powers try to have control over the inrealms (Micro, Meso and Macro) through imposing its own system rules in a way that often ignores the conditions of the civilization dialogue, acculturation or desired development processes. It even tries to practice pressure to change the structural rules in the other realms, without taking into account the privacy of these realms, which reinforces the existence of the semi-permanent conflict condition. 
Nile Valley Journal of Human studies and social research

The following lines will highlight the main concepts and relations upon which these three hypotheses have been built;

\section{2- Basic Concepts and Relationships of (CRT) \\ 2-1Social Agency:}

Primitive man does not have rules to organize the behavior, but yet he had the mind- the tool by means of which these rules could be established. Primitive man's agencies were necessarily motivated by his need to meet the social, biological and spiritual requirements, which was not an easy task, especially if we take into account the hard natural conditions surrounding him at that time. Yet, he managed to utilize the mind to satisfy his needs through interacting with nature, thinking of the potential power that controls nature and settling the conflicts among individuals. It is at that point that the first group managed to lay down these behavior-organizing rules, and also to the emergence of the preliminary state of the social structure. Naturally, throughout long centuries, change took place slowly.

As such, we are in agreement with the conclusions of the Social Theory on the change factors in the modern age, which include: population growth, environmental hazards, conflicts, wars, charismatic persons and the exceptional leaders in the history of societies, Prophets and Messengers, the heavenly revealed religions and manmade laws, the major philosophical thoughts, political theories and regimes, economic developments, rationality, education, scientific discoveries, technological advancement, manufacturing, the origin of the urban 
Nile Valley Journal of Human studies and social research

(ISSN : 2536 - 9555)

communities, institutionalism, work division, bureaucratic systems, law, the change of values and the communication revolution.

The multi-dimension change resulting from the technological or intellectual development, or the major religious shifts, or revolutions and conflicts leads to the redistribution of power or fortunes or the social statues. It may also lead to making change in the ways of life and even turning them into new phase through the modern technological means, or the new ideas and thoughts, or the political, economic, social formation emerging in the aftermath of revolutions and conflicts.

To cope with the material, developmental change, reflective (collective, or authoritarian or exceptionally individual) agencies come into existence to restructuration rules, to take advantage of material developments in the frame of adaption to change. If change is related to social relations (conflict or integration), reflexive agencies expand or completely alter the old structural rules.

\section{2-2The Structural Rules Concept}

The structural Rules represents the main concept for (CRT). we defined the concept as abstracted actions free from time and space, has a linguistic, value and standard connotation, evoked by the agent to organize the motives and achieve the dynamic, intellectual or spiritual purposes. Accordingly, we shall answer the following questions to clarify the concept and its dimensions: How does the rule emerge? How does it perform its function? What are the kinds, definitions, social scopes and life cycle of rules?

\section{2-2-1 The origin of the structural rules}

Depending on the fact that the agency comes before the structure, the reflective agency that achieves Dynamic and

$$
\text { (6) }
$$


Nile Valley Journal of Human studies and social research

tangible benefit to man or that may achieve one of the major values desired by him may be achieved. We thus can name it the structural agency. For the agency to eligible to be described as "structural", it shall meet the conditions of acceptance, spread and repetition.

To say that the agency is free from place means that it becomes approved and spread outside the local society in which it appeared. To say that the agency is free from time means that it becomes a frequently repeated beyond the time in which it emerged, and by the passage of time it becomes a model agency (that has linguistic and symbolic meaning indicating its value or criterion). Yet, in case there is no rule for the new agency, it itself becomes the rule organizing the similar agencies. The "rule of burying the dead body" is a famous case in point; the children of Adam learnt this rule through imitation. It became an approved, spread and repeated agency that regulates behavior when burying a dead in most societies today.

Then, this rule extended to be closely connected with the religious ritual and beliefs, which led to the emergence of new agencies that are different in some societies, like burning, scattering and throwing the dead body. Irrespective of the reason, this new agency has been approved, spread and repeated, to the extent that it became a rule that regulates the behavior and rituals of burying the dead in these societies. Now, we shall move to the second question: How does rule perform its function in regulating the social agency?

\section{2-2-2 The function of structural rules}

The Structural Rule performs its role in regulating the social agency through two coinciding operations: (1)

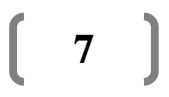


Nile Valley Journal of Human studies and social research

(ISSN : 2536 - 9555)

confirming the rule in the collective mind through socialization, where the former generation is keen to transfer the standards of the rule to the next generation, and teach individuals the meanings of the rule in terms of language to be used in the process of communication. and teach them the utilitarian and absolute value of the rule. It is important to note that the means of confirming the rules differ according to the type of rule (dynamic, intellectual, spiritual), and here the importance of the methods and means of spontaneous socialization within the family or institutions of modern education.

(2) Establishing a system of symbolic or physical penalty (reward or punishment) to sign the agents according to the type and degree of compliance or violation of the rules. Of course, there is a close connection between the system of the penalty and the processes of crystallization of the rule in the collective mind.

After setting the penalty system and crystallizing the rule in the collective mind, the structural rule gets effectiveness and turns into a liquid rule. Liquidity here means that the rule is not only laid down in the minds of individuals, but also appears directly in their behavior. That is to say that the agency gets back its indication of time and place and thus becomes alive and present in the social relations, situations and interactions as well as the evaluation of things. Thus, when an individual commits something that violates one of the structural rules, he will be directly met with reactions disapproving his violation, or that he may be bitterly reproached or even be subject to the application of a legal penalty. These reactions mean that the rule is effective and liquid because it is fixed in people's minds, present in time and place and personified in their behavior. 


\section{2-2-3 Types of rules by target agency:}

The system of the structural rules is composed of effective and interactive rules, which can be classified into three main sets: the Dynamic rules, the intellectual rules and the spiritual rules. Each set of rules has its own part in regulating the social agency and directing it the course agreed upon by the group. We must remember that each set of rules is divided again into interactive rules, institutional rules, and tunnel rules, such as interactive dynamic rules, institutional dynamic rules, counterdynamic rules, and so on.

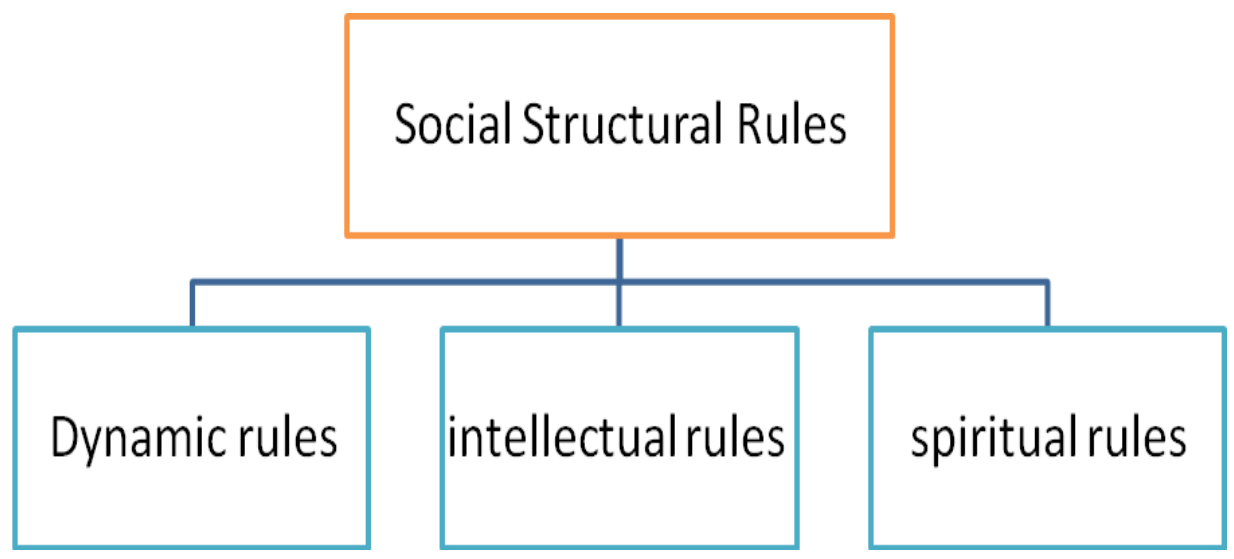

(1) Definition of the Dynamic Rules: They refer to all the rules governing human behavior that enable an individual to maintain his or her personal life, its continuity, and the survival of the group to which the person belongs. They include (1) rules governing the satisfaction of basic individual needs, such as food, clothing and housing. (2) rules saturated with the instincts

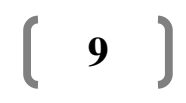


(ISSN : 2536 - 9555)

of reproduction and the continuation of the species, such as the rules of marriage and cohabitation, nuclear kinship such as parenthood and brotherhood, extended kinship like clan, tribe, nation and ethnicity, and (3) rules saturated with the instincts of survival of the group, such as power and control of resources, and the need to save life against others and preserve the environment to avoid the risk of annihilation.

The most important institutions embodied in these rules: the family, political institutions, economic institutions, military and security institutions. It is well known that the dynamic rules are the field of research of most branches of sociology, some branches of psychology, social psychology, and some branches of anthropology, political science and economics.

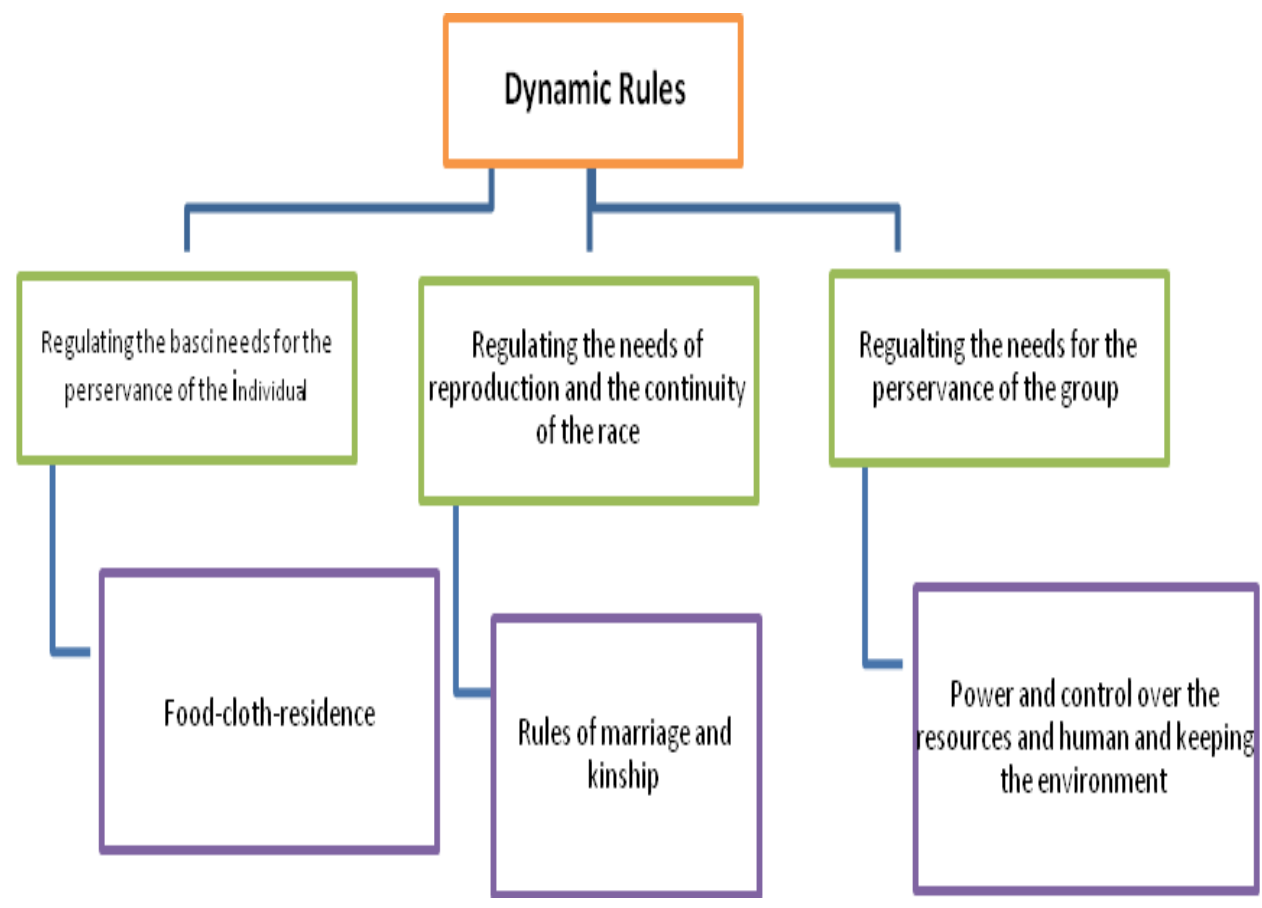


Nile Valley Journal of Human studies and social research

(2) Definition of the Intellectual Rules: They refer to all the rules in which a person uses his mental abilities and physical skills to manage his life and enjoy it in some way It distinguishes from the dynamic rules of the principle of urgency associated with dynamic rules. They include (1) rules organizing discovery, exploration, invention, and enjoying life: (science, technology, arts, literature, sports, entertainment and tourism). (2) rules organizing the social interaction (solidarity, altruism, friendship, love, etc.), and (3) rules organizing the individual aspirations within the group: (assertiveness, self-realization and self-evaluation). The most important institutions that embody these rules in the modern era are the institutions of education and scientific research, cultural institutions, sports, leisure and tourism institutions. On the intellectual rules and associated actions and practices, sociology meets human sciences, arts and literature, as well as giving and taking with some branches of psychology, anthropology and pedagogy, along with most branches of philosophy.

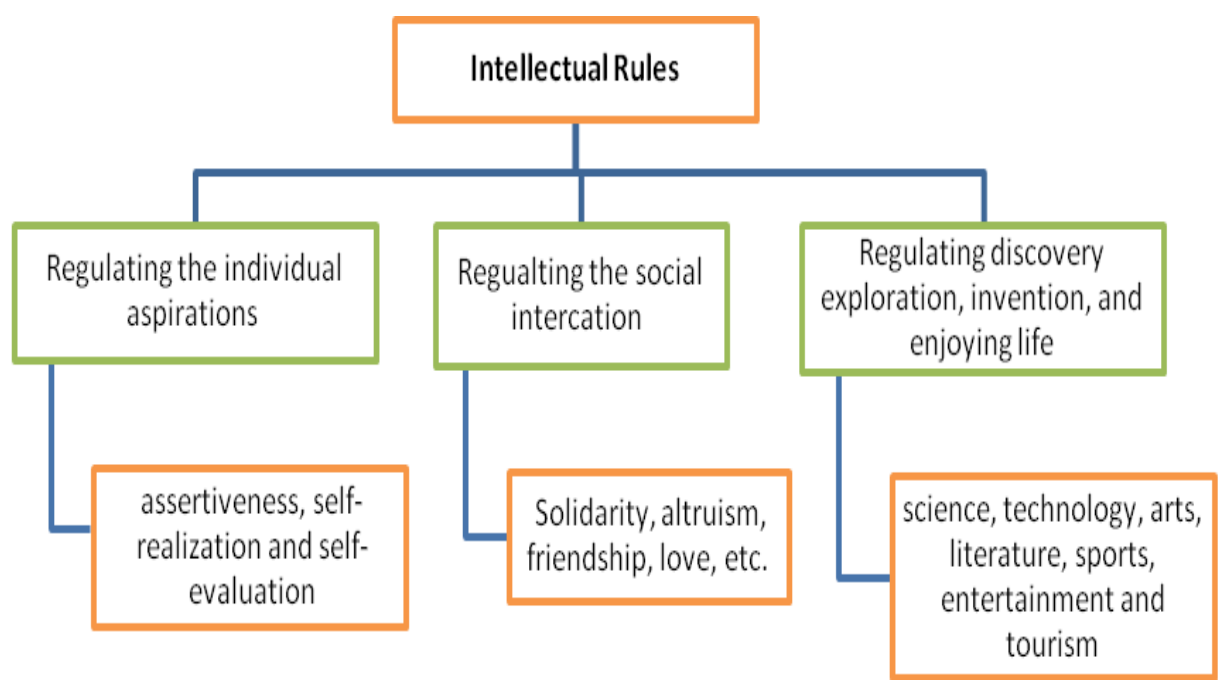

11 
Nile Valley Journal of Human studies and social research

(ISSN : 2536 - 9555)

(3) Definition of the Spiritual Rules: They refer to these rules organizing the religious practices and the ethics that are agreed upon by the community, either through philosophy, or wisdom, or positive laws or a heavenly revealed religion. The spiritual rules, in general, contribute also to forming the special criteria of the structural rules. They are further responsible for forming the philosophy of punishment for all the structural rules including the spiritual ones. Naturally, these rules shall be personified in the religious institutions. They are also partially personified in the legislative institutions that work on laying down the philosophy of penalty.

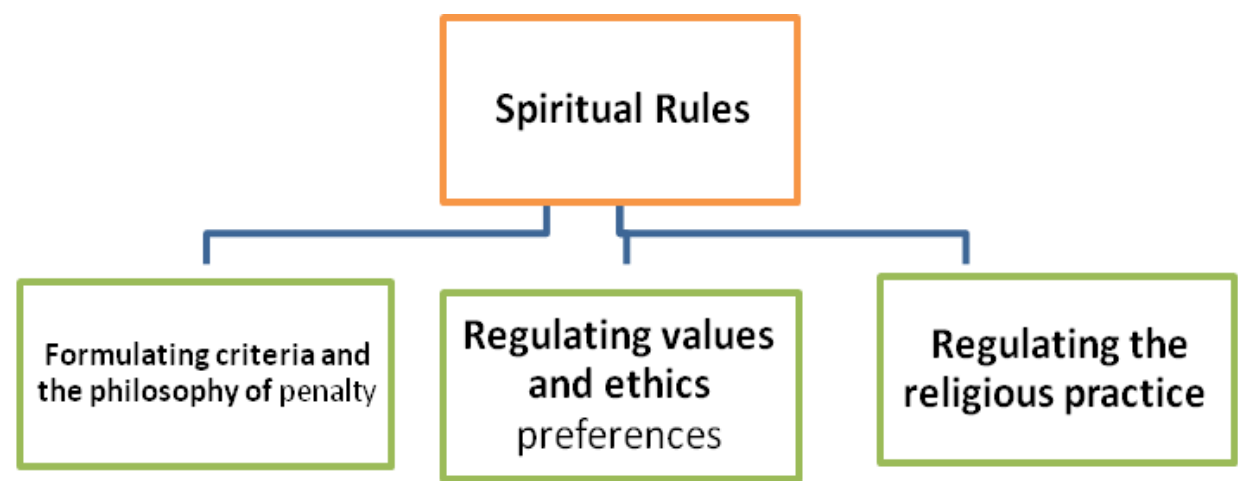

It is natural that each of the main and secondary structural rules has acquired something from the history of the group and from the alternation of change factors. In addition, the order of importance of these rules is also linked to the group's vision of the world in the light of the surrounding material, environmental and social conditions. At that point, we can deduce a definition for the concept of the Social Privacy used ambiguously in literatures, as follows: "It is a defined relation that connects the components of the social structure 
(interactive, institutional and tunnel). the content of the structural rules accumulated historically and the relative importance and strength of each type in a given society and a specific time.

It should be noted that these rules do not function in organizing actions independently of one another, on the meaning that the actual motive for achieving one purpose of dynamic, intellectual or spiritual purpose does not only clash with the relevant rule but also collides with the other two rules. And there is a conflict between these three forces within the human mind. The actor who chooses to wear a particular costume does not only look at dynamic rules, but he respects the intellectual rules (the community's culture of fashion), and often in our Arab society, which takes into account the religious rules that set the standards of religiously acceptable dress.

Sometimes the conflict of rules leads to indecision, when the three pressures on the mind are equal, and here the agent is forced to suppress the impulse or postpone it, but some of the dynamic motives cannot be suppressed or delayed, here the agent resorts to an adjustment to the purpose in order to reduce pressure, or in a radical solution, the agent achieves his purposes through the dark tunnel structure, where the counter rules allows full satisfaction of the motives and desires.

\section{2-2-4 Classification of Rules by Type of Sub- structure:}

We have stated that social structure in any social realm is a three-fold structure, which are interactive, institutional and dark tunnel structures, each of which has its own type of rules: (1) common interactive oral rules (2) 
(ISSN : 2536 - 9555)

formal institutional rules (3) counter rules to both previous. Returning to the above example, an agent who chooses to wear a uniform is governed by interactive or institutional rules. Sometimes there is a conflict between the two rules, as was the case, for example, of preventing Muslim women from wearing headscarves in France in the workplace. which could lead to emergence of active movement agency among the Muslim community in France aimed at changing the institutional rule. In the same way, counter-rules are closely related to the subject of fashion, such as members of a banned political or religious group, who are active in wearing uniforms expressing their identity and belonging to this or that group, in defiance of the interactive and institutional rules.

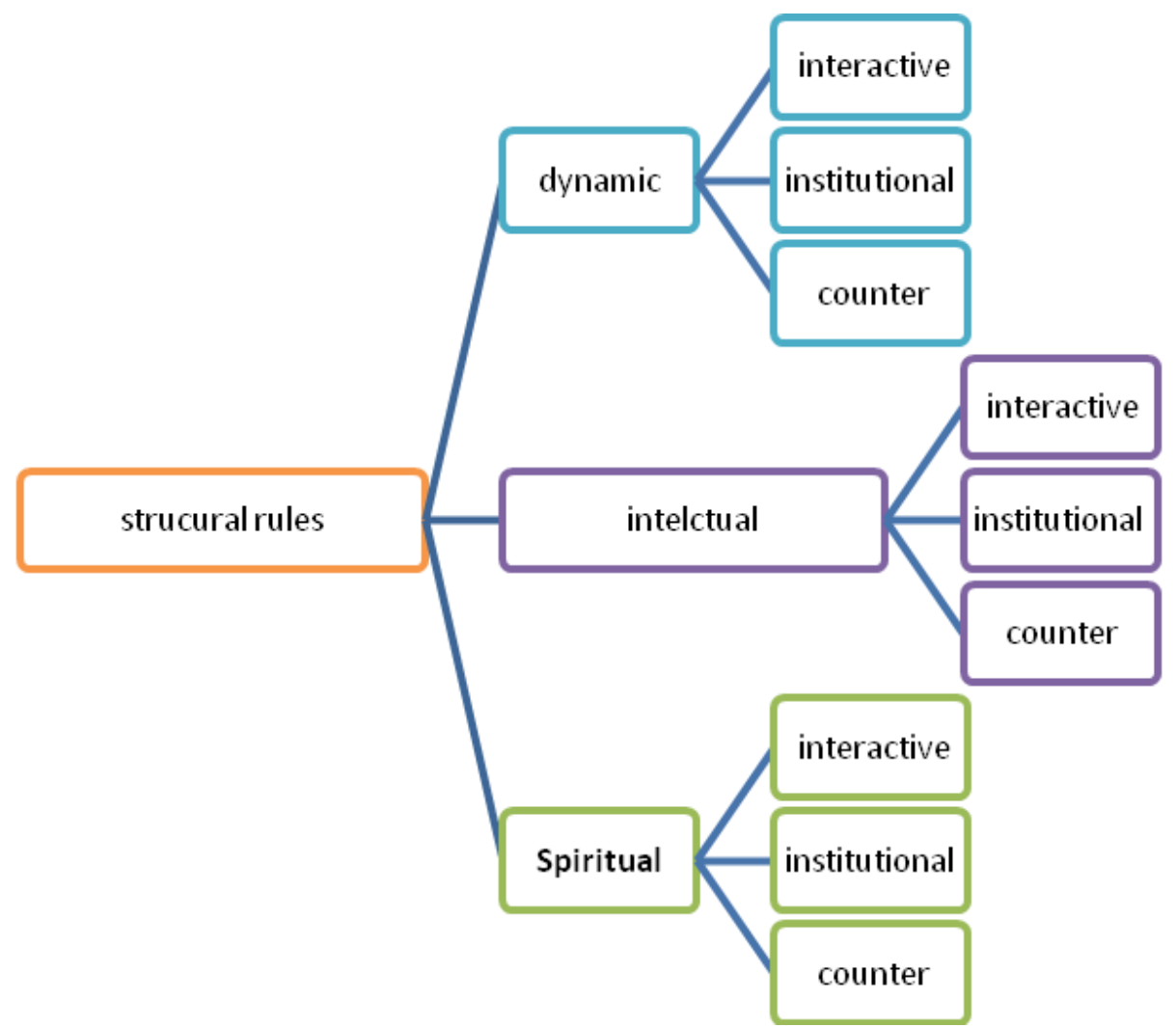

14 
Conflicted Rules Theory (CRT)

A New Arab Theory in Sociology

Dr. Ahmed Mousa Badawi

Nile Valley Journal of Human studies and social research

\section{2-2-5 life cycle of the structural rule:}

By knowing the function and characteristics of the structural rule (crystallization, penalty and liquidity), we can understand the life cycle of the structural rule. In other words, the rule that gradually loses its effectiveness and liquidity, for a reason or another, urges the group to be loose in applying the penalty, which is why the rule, under this case, remains for a short period of time as one of socialization requirements after which it shall disappear as a result of the emergence of a new rule. This course is complex and not simple. Each rule has a number of subrules, auxiliary or secondary. It represents a circle of protection that prevents the change of the mother rule for the longest period, and in order to lose its effectiveness and liquidity, the branches must be weak first.

Finally, we stress two things. First, the strength of the Structural Rule is infinite, and that its part in directing the social agency is temporary, no matter how long is the period of time. The social change factors, renewal, inventions, technological advancement, cultural contact and even wars and conflicts lead to making change in the strength and function of the rule. Sometimes, some strong rules change into legend or fake or biased ones that must be removed and replaced. Second, rationality gives the collective mind the flexibility of commitment. What do we mean by that? The ability acquired by the collective mind through strategic socialization systems stimulates reflection on change, exploration, surprise, and conflict management, provided that the authority of penalty is human, just and equal, to allow for differences and to create new actions that expand or change rules. 
(ISSN : 2536 - 9555)

\section{3- The Three-fold Social Structure}

For each of the five social realms, there is a social structure composed of three independent and tangled structures: the interactive common structure, the hierarchal institutional structure and the dark tunnel structure. We can offer a brief definition for each of them after which we shall highlight the characteristics of the dark tunnel structure, ending up with the relation that gathers the three structures together.

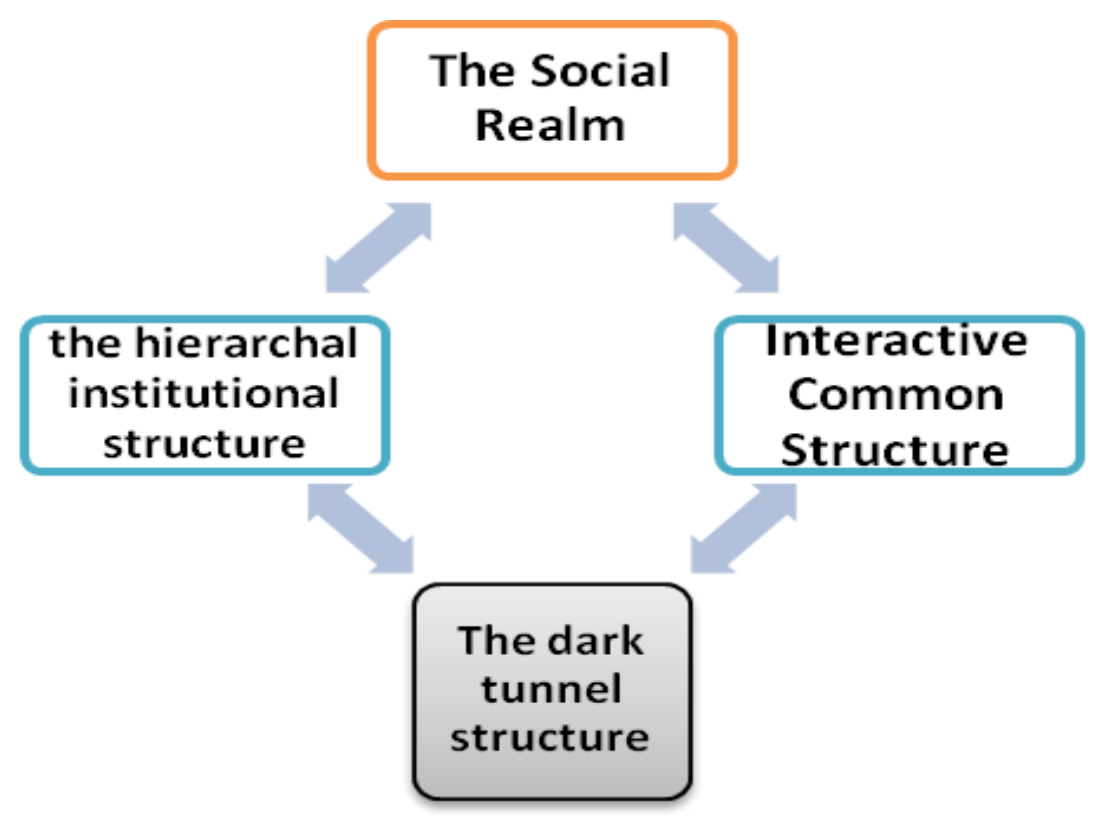

\section{3-1 Definition of the Social Structure}

The interactive common structure: It consists of oral structural rules (dynamic, intellectual, spiritual)that organize the social interactions, relations and positions that are inherited by consecutive generations and which are spontaneously crystallized in the collective mind through socialization. It is historically accumulated 
through the various material and social life experiences. Oral rules have a traditional physical or symbolic penalty.

The Hierarchal Institutional Structure: It consists of institutional structural rules (dynamic, intellectual, spiritual)that regulate the intentionally rational agencies and the hierarchal positions within the single institution and the other institutions. The education institutions along with the other official institutions concerned with socialization are responsible for the crystallization of the institutional rules in the collective mind. These rules have the power to apply material penalties which are defined by the institution internal system without any contradiction with the philosophy of penalty approved by the society through general laws and constitutions.

The Dark Tunnel Social Structure: It consists of counter-rules (dynamic, intellectual or spiritual) of oral or institutional rules, that organize the intentional collective agencies viewed as illegal by the community. It has an internal system for socialization and sanction which targets the permanent or the temporary members. It is logical and realistic that not all rules can be counter within tunnel construction, and these counter rules do not always have negative connotations. Sometimes the rules are contrary to the exploitative or discriminatory relations prevailing in both institutional and interactive structures.

The following lines shall highlight a necessarily, detailed description for the characteristics of the Dark Tunnel Structure relying on the point that the Sociological Theory often focuses on the interactive common structure and the institutional structure while, for a number of reasons including the difficulty of studying the special phenomena 
Nile Valley Journal of Human studies and social research

(ISSN : 2536 - 9555)

of this kind in the light of the empirical study, neglecting the Dark Tunnel Structure.

\section{3-2 Characteristics of the Dark Tunnel Structure}

The groups forming the Dark Tunnel Structure can be divided into four, as follows: (1) cells of institutional corruption; (2) cells of the organized crime; (3) secret political, or religious, or social or cultural cells; and (4) cells of terrorism. All the five social realms agree on that aforementioned classification; yet there are big differences in the categories under each of these kinds. For example, a group that practices prostitution can be classified under the organized crime according to some realms, and under social practice that guarantee the freedom of the person according to other realms. The same applies to these secret groups resisting occupation; they may be viewed by the occupier as an intentional crime, while other realms will view it as intentional legal practice.

The Dark Tunnel Structure is characterized with Selectivity, meaning that it does not include but those who have the motive and the ability to intentionally make illegal agencies. Inclusion and exclusion of new members take place through direct social relations that take place in the Micro Social Realm. In some special groups of organized crime and also in some secret cells, various generations within the same family can inherit the same intentional illegal agencies, which means that the crystallization of the anti-rules closely connected to the collective mind of particular families.

It is also characterized with its ability to convert from the dark condition to the surface of the social life through the various processes of changes that re-structure the political, or social, or cultural or economic conditions, a matter that leads some of the secret cells to leave the Dark 
Nile Valley Journal of Human studies and social research

Tunnel and engage in the two interactive and instructional structures. In the same connection, there are some secret groups that combine between appearance and disappearance on grounds of the appearance of some antirules allowed by the direct interactive structure and the institutional structure and the disappearance of some others posing threats for the two structures. The Muslim Brotherhood Group is a case in point.

This is structure is further characterized bya strong vertical and horizontal network. As for the horizontal kind, it means that the one single group automatically connects with its counterparts in the other social realms through a complementary integration relation. The small drug gang is a case in point; it connects with a larger group within the society. In the same time, it is connected with similar groups in out-realms. As for the vertical kind, it includes the three groups (corruption, crimes, the secret cells and the cells of terrorism); they may interrelate with each other to achieve a particular benefit within in-realms or out-realms. The terrorist group connects with the international weapon gangs which are, in turn, connected to a corrupt local institution that smuggles weapons into societies. The same organization may also be a source fir selling stolen monuments to international gangs, as is the case in Iraq.

\section{3-3The Relation between the Three Structures}

First of all, we should state that the Dark Tunnel Structure is always in permanent conflicts with the two interactive and institutional structures; these conflicting relations may diminish but they never disappear at times of stability. They even become worsen at times of unrest, 
Nile Valley Journal of Human studies and social research

(ISSN : 2536 - 9555)

official authority weakness, economic deterioration and absence of justice and equality.

As for the relation between the interactive structural rules and the institutional ones, we can spot the following three relations: (1) Coexistence rules: it is defined as this case emerging between the oral interactive rules and the official institutional rules due to the existence of common factors which reach neither the level of integration nor that of conflict; (2) the integrative rules: this relation take place when the indications of each of the two systems belong to one origin yet differ in the level of development; and (3) conflicting rules: this relation takes place when the indications between the two systems are contradictory, a matter that leads to the emergence of a conflict between the interactive common structure and the institutional structure.

Therefore, the institutional structural expands on account of the direct interactive structure, that is, whenever the factors of change incline to civilization and intellectualism, integration relations, followed by coexistence relations, will prevail. Also, the conflicting relations will weaken. On the contrary, the direct interactive structure expands on account of the institutional structure; that is to say that whenever the factors of change incline to deterioration, especially in the transitional stages and at times of conflicts and wars, conflicting relations will prevail; they will be followed by the emergence of the coexistence relations on account of the weakness of the integration relations.

\section{4- Mechanisms of change within the social world}

We assume that the change of rules in interactive and institutional structures (without neglecting the effect of 
counter rules in dark tunnel structure) occurs in three ways: first, through collective agencies which are approved, spread and repeated; this way takes a relatively long period of time until the change of the rule occurs. We have two other ways to make change: through the exceptional individual agencies and the authoritarian agencies, which both lead to a swift change in the rule, as will be shown later. But, before highlighting this point, we shall review the relation between the well-established rule and the routine, ordinary agency to be able to understand these Mechanisms of change.

We can classify the ordinary or the routine agencies in terms of the two limits of total approval and total rejection, as follows: (1) the total approval limit: it occurs when the routine agency adheres to the all the criteria of the relevant rule, and thus the agent will receive the highest reward in return for this adherence, and the agency will still be approved as long as it lies within the frame of compliance with the rule with suitable change in the value of the reward; and (2) the total rejection limit: it takes place when the routine agency contradicts all the criteria of the relevant rule, and thus the agent will be punished with the severest penalty, and the agency will still be rejected as long as it does not reach the minimum level of compliance.

At that point, we should take into account that fact that the agent (the person) violating the rule in the routine conditions does not challenge the rule, nor does he deny it. On the contrary, he believes in its value, accepts its criteria and submits to the system of punishment, be it incorporeal or material, imposed as a result of the violation. This, in 
Nile Valley Journal of Human studies and social research

(ISSN : 2536 - 9555)

actuality, contradicts the intentional collective illegal agency made by groups (corruption, crime, secret organizations, and the cells of terrorism). In actuality, the Dark Tunnel Structure agency starts from rules which counter the extremely relevant interactive and institutional rules.

\section{4-1 Change through the Social Collective Agencies}

The social collective agencies can be classified into two kinds: spontaneous collective agency and active collective agencies. Let us starts with reviewing change through the spontaneous collective agencies; when the social realm exposes to one or more of the factors of change, a new social agency will come to existence in reaction to that change, an agency that emerges in response to collective motives defined in light of the group's common factors; it shall reflect the beneficial or the absolute value of change for the group. At that point, the new (spontaneous collective) agency will be conflicting and challenging with the value and criterion indications of the stable rule; that is to say that it will be neither approved nor rejected because the stable rule does not have sufficient indications to support this new agency. Also, we should take into account that the new agencies emerged as a result of one of the factors of change, as have been previously mentioned, expand the rule in light of the adaption process, while the new agencies resulting from conflict or integration lead to the quantitative change of the structural expand or change the rule qualitatively.

But, before the occurrence of expansion or change, the political authority (often conservative) will depend on the partial tools it has to provide temporary solutions to classify the new agency, including: (1) the revival of an outdated old rule; and (2) interpretation of the new 
agency in the light of the closet rule to which it may belong, yet the new agency's insistence on spread and repetition lead by the passage of time to expanding the structural rule or replacing it with a new one.

For example, since the early $20^{\text {th }}$ century, a number of Arab Renaissance pioneers asked for applying the democratic ideologies and thoughts of the west on the Arab, Muslim countries. In actuality, their demand took the form of newly-emerged agencies in accordance with the system of the stable structural rules, that is, they are neither approved nor rejected. For this reason, the political authority resorted to interpreting the thought and the democratic practice in the light of the consultation $(E l-$ shoura) rule. In fact, defective forms of the semidemocratic institutions came into existence, yet they did not live long, because interpretation did not conclusively decide on the matter, for the indications of consultation were not identical to the rules of democracy. By the passage of time, the democratic ideology and practice turned from a newly-interpreted agency into a new rule to organize the political agency in most all the Arab countries.

As for the second kind of agencies which is "the active collective agency", it is defined as the organized efforts exerted by a number of people to change some structural rules in order to achieve defined political, or religious, or social or cultural objectives. It is divided into two kinds: integrative active agency and the conflicting active agency. As for the first kind, active agents have alternative structural rules called the ready-made rules which they try to impose on the social structure, either through 
Nile Valley Journal of Human studies and social research

(ISSN : 2536 - 9555)

negotiation or practicing pressure on the current authority. Sometimes, the integrative active agency managed to change or modify some of the structural rules to allow them acquire new criteria, especially in these cases which are approved by the rest of the society members like the labor, syndicate, law, women and environment protection movements as well as some ethnic movements.

But when the ready-made rules are against the interactive and institutional rules, the active agency is classified as a conflicting one. It will be even dominated by secrecy and thus becomes part of the Dark Tunnel Structure. Most often, violence and terrorism are used to change the reality, and thus the agency becomes in a direct conflict with the authority and the society. The religious and terrorist groups scattered far and wide in the Arab and Islamic world is a case in point. In case of the weakness or neglecting of the authority, the active conflicting agency may dare to apply the system of the penalty of the anti-rules in some cases and events, challenging thereby the stable structural rules and the legitimate penalty authority, which leads the society to the edge of abyss.

\section{4-2 Change through the Authoritarian Agencies}

Change through the authoritarian agency causes some old rule to be out of order and also imposes alternative ready-made rules, yet what makes it different from the active agency is the authoritarian agent has the official penalty system and thus activates the authority of penalty to obligate the society members to it after imposing the rule. There are three kinds of the authoritarian agencies as follows: progressive agency, abusive agency and weird agency. As for the first kind known as the progressive 
Nile Valley Journal of Human studies and social research

authoritarian agency, it intends to make development in one of the social fields, and thus the authority resorts to borrow an active rule from out-realms or even invent a rule and imposes its application with the authority of violence entitled to it. As such, fields which are closely connected to the new rules will be developed.

Sometimes, the new, social, incubating rules, irrespective of their beneficial value, are not enough, because the social agencies and practices work in terms of the old stable rules. Thus, to suffice with the new rules will not lead to making the desired change, and thus the new rules shall be crystallized in the collective mind.

To fail in achieving that (The state of Saudi society now) means that both the old and the new rules coexist with each other: the old settle in the direct interactive structure, while the new will incline to the hierarchical institutional structure; the old have the authority of the corporeal and incorporeal penalty applied in accordance with traditions, while the new have the authority of the material penalty; the old have to do with the daily life realm and the direct social relations, while the new have to do with the official institutional realm, which result in confusion in the extremely relevant social agencies because of the confusion and the overlap of the two types of rules.

As for the second kind of change that takes place through the abusive authoritarian agencies, it takes place when the ready-made rules are chosen on basis of abusiveness, exploitation in the redistribution of power, wealth and status in favor of a class, group or colonizer. In many cases, the agents in the Dark Tunnel Structure direct 
Nile Valley Journal of Human studies and social research

(ISSN : 2536 - 9555)

these abusive agencies via their representatives inside the hierarchical institutional structure. In this case the members of the society will enter into a state of structural reality upon which the individuals will have to unwillingly adhere to the ready-made rules. The scope of these rules is limited to the official institutions only, and thus the two old and the new rules enter into a state of conflict, not coexistence as is the case with the authoritarian progressive agencies.

From time to time, weird authoritarian agencies, relating to the strange ruler imposing confusing structural rules whose benefit cannot be proven, may come to existence, and thus the members of the society arbitrarily submit to them. The penalty code of these rules is most often based on a great deal of abusiveness and irrationalism, which leads to the disappearance of the old rules from the life of people for fear of persecution, even on the level of interactions and direct relations. Historical evidence indicates that this kind of rules collapse with the leave of the ruler for any reason, leaving behind complete chaos in the entire society. As that point, the direct interactive structure will expand at the expense of the hierarchical institutional structure, and thus the Dark Tunnel Structure will penetrate into the details of the social life. The Iraqi and Libyan cases provide striking examples for the impact of this kind of the weird authoritarian agencies.

\section{4-3 Structural Change through Exceptional Individual Agencies}

The third pattern of structural change is made by exceptional personalities in the history of societies. There are two types of this change: progressive exceptional 
Nile Valley Journal of Human studies and social research

agencies and abusive exceptional agencies. The first type is done by great personalities like Prophets, Messengers, reformers and charismatic leaders. Although they impose structural rules as other persons of authority do, there is a crucial difference for two reasons: First: exceptional personalities have a wide public acceptance, in addition to the absolute trust they gain from members of the society. This creates a case of direct acceptance of the new structural rules they call for. Second: these personalities are basically concerned about the greater good. Owing to their mental, spiritual and emotional vision and their faculties, they spot the weaknesses in the social structure and thus try to change the rules that have causes this weakness. In most cases, this change causes leapfrogging in the history of communities and accelerates social change.

However, there are other abusive exceptional agencies that appear within the dark-tunnel structure causing dramatic change in routes of the conflicted active social agency. Thus, the ready-made rules imposed by these personalities become like explosive bombs in the society. In this regard, we can recall persons like AbulA'la alMaududi and Sayyid Qutb, who put the basic rules of terrorist groups in the Arab and Muslim worlds. The following diagram summarizes this Mechanisms: 


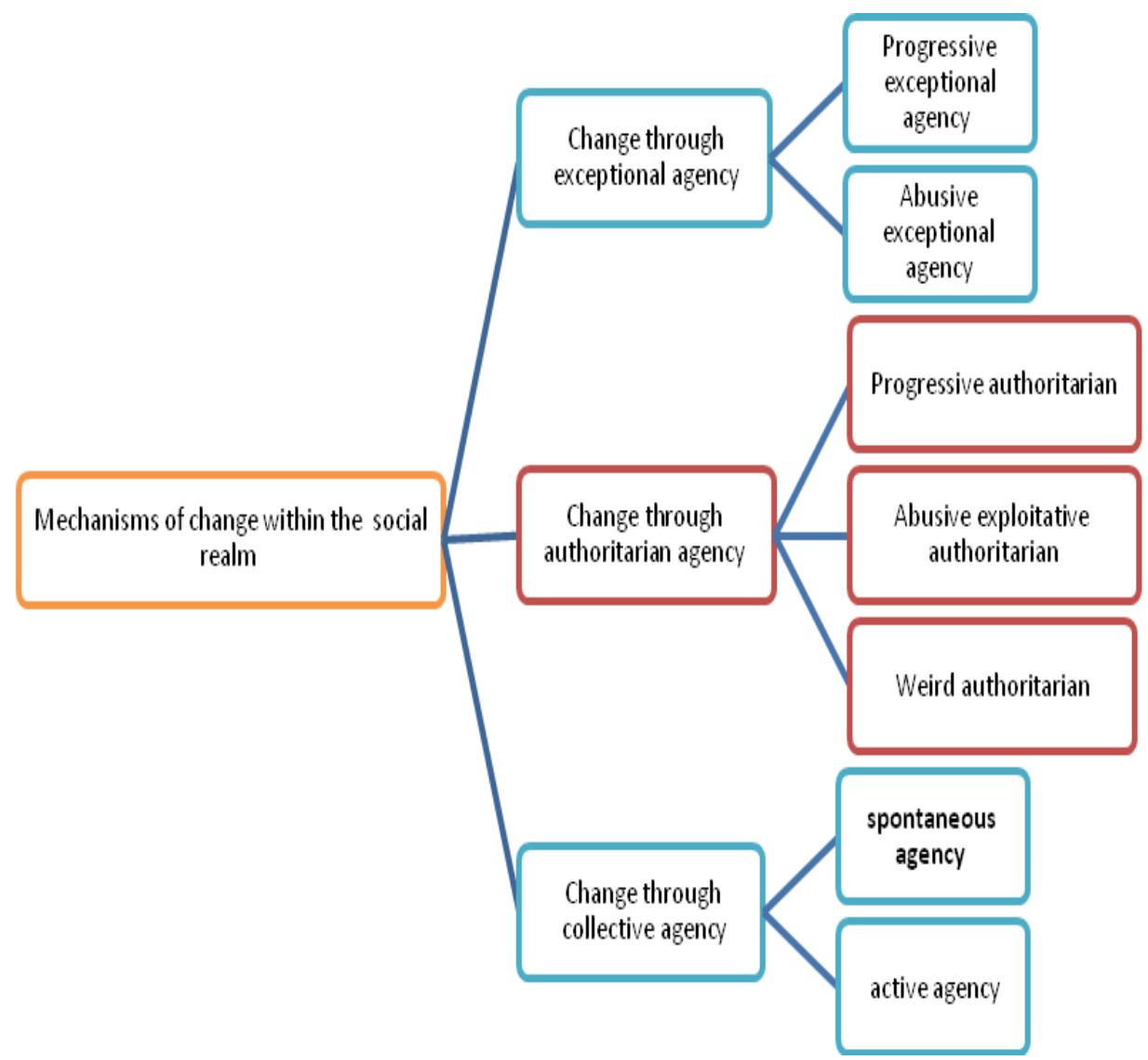

Thus, structural rules can expand or change through social interactive spontaneous social agencies done by members of the community in response to various change factors. They can be replaced with ready-made rules through the active agencies or through authoritarian agencies, where some of which may create positive effects or negative effects either intended or unintended, regardless of the value of the new rules. Structural change may happen through inspiring exceptional personalities, and in this way it will be received with direct acceptance and appreciation. It may also happen through abusive 
Nile Valley Journal of Human studies and social research

exceptional personalities that establish for the dark-tunnel structure. These mechanisms cause change in the compound social structure within the same social realm. Change may extend to other social realms, as stated in the first hypothesis. Therefore, we will elaborate on interaction and interlink ages that connect structural rules in the five social realms.

\section{5- Classification of Social Realms:}

man, in this age of globalization, lives in five interactive social realms, ranging from simplicity to structure and complexity. Each of these realms represents an independent social fact (social structure, demographic characteristics, pattern and production relations, spiritual and intellectual system). We divide it into two main groups: the first is called IN-Realms which consist of: (1) small social realm(Micro),the field of emotions, feelings and direct and basic social interactions in human life. (2) communities and institutions realm (Meso), (3) the big society (Macro)which connects the small and middle realms through a central institutional network. The second group is called Out-Realms, which includes (4) the (Reign Society) which includes geographically contiguous communities connected through integrated and interactive or conflicted relations at various political, economic, social and cultural levels, and (5) the (Global Society). 
(ISSN : 2536 - 9555)

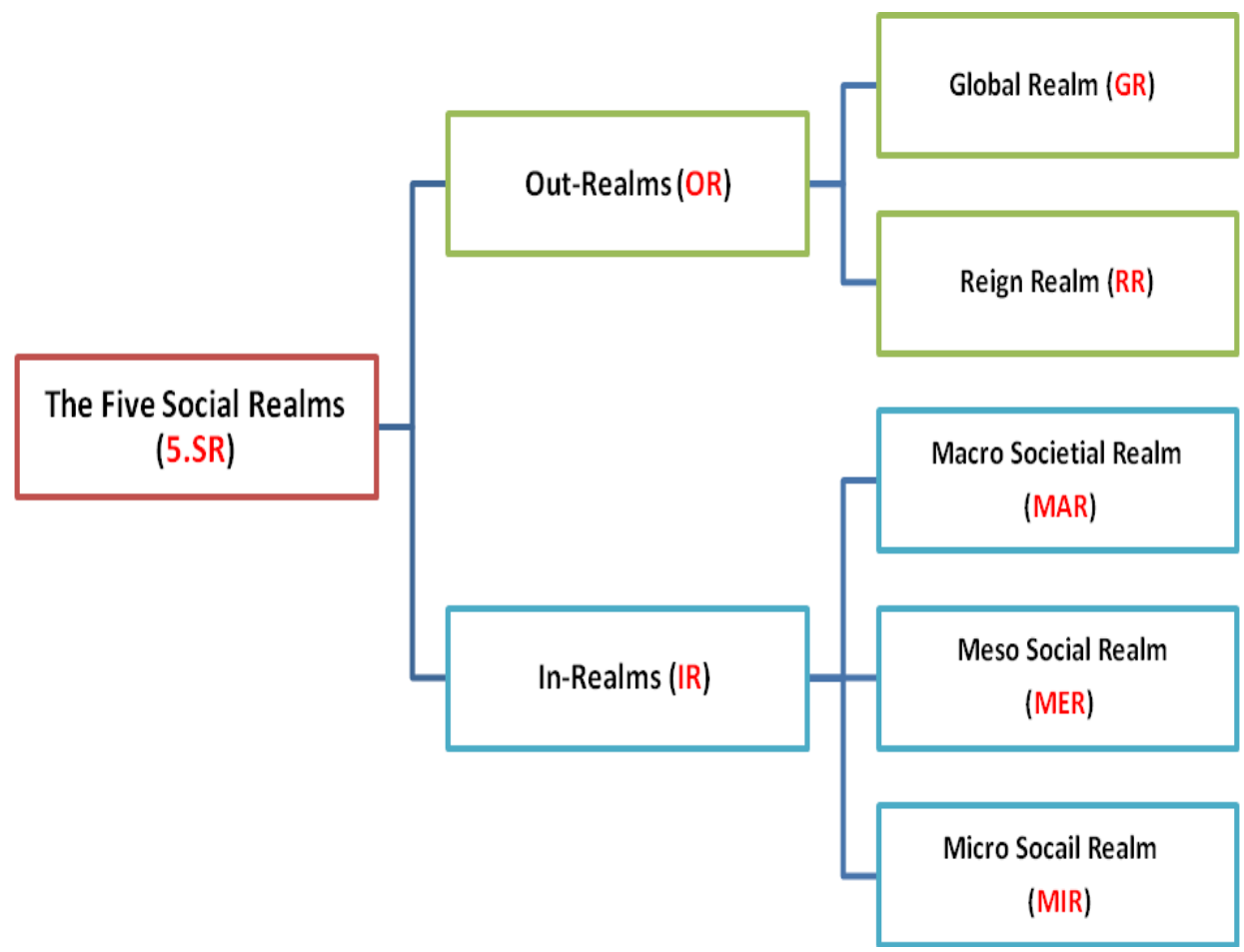

Of course each of these realms has its theoretical and methodological methods to search it. It is known that sociological theories for a long time have been divided into: micro theories and macro theories. However, contemporary theories call for studying social realms as relatively independent, but interactive realms. These theories found it suitable to study four of the above five realms excluding the region realm.

\section{5-1 Relationship between the Five Realms:}

The relationship between the five social realms can be understood by measuring the degree of homogeneity - or the heterogeneity - that exist between the five realms on three levels: (1) the dynamic level: political, economic and social systems, demographic, ethnic, class, and 
Conflicted Rules Theory (CRT)

A New Arab Theory in Sociology

Dr. Ahmed Mousa Badawi

Nile Valley Journal of Human studies and social research

environmental structures, security and military institutions. (2) intellectual level: education system, cultural system, technology and scientific research, entertainment, tourism and sports institutions etc. (3) spiritual level: the system of religious and moral beliefs and values.

In general, increasing homogeneity in the in-realms leads to increased autonomy and stability, in addition, social relations within these realms tend to secure integration or co-existence, reducing the chances of interference from out-realms. vice versa.

\section{5-2 The need for regional sociological research:}

We find it necessary to conduct intensive sociological studies on the region realm, and not to leave this arena to political and economic sciences. For example, there is a need to change the scope of Arab sociological research, from the local research into the regional one in order to cover: (1) studying the temporary workforce migrations between societies of the region, and the resulting class structure or the socio cultural change in both expelling and receiving communities; (2) studying the relations and interactions of regional ethnic structure across political boundaries.(3) To study the spread of political, religious, social or cultural ideas or movements among the societies of the region and their profound impact on social change within these societies.(4) studying the dark tunnel structures of In-realms and their relationship with the Out-realms(region or global). (5) studying the relationship of societies to the regional environment in which they live. And (6) The notion of Arab integration may have a different meaning other than the observed dramatic 
Nile Valley Journal of Human studies and social research

(ISSN : 2536 - 9555)

conflicts, if there is a distinct scientific production in sociology of region.

Thus, studying the sociology of region realm may be the most important and decisive point on the medium and long terms to create a successful social life across the Arab world. Through this gate, change in all interrelated social, cultural, economic, and political phenomena may be explained. Thus, to exclude the region realm from investigation may lead to misunderstanding the relationship of the Arabs with the different social realms, and would create a knowledge gab that must be bridged.

\section{6- Conflicted Rules Theory's Interpretation of Change - an applied example:}

As we have elaborated on the relative weight for structural rules within the same social realm, we assert here that there is no, in principle, a social world in total conflict with the lower or upper realms in the structure. Thus, some structural rules are in integration with the corresponding rules in other rules systems, while some rules are in conflict with these systems. For example, spiritual rules organizing religious practice may be consistent in two or more social realms, however, they have contradictions with other rules, which may result in conflicts or even wars.

We have mentioned that the system of structural rules organizes the social agency through putting the suitable standards of the agency and raising individuals up to understand the significance of the value in terms of its moral and linguistic structure, to realize its social significance and to state the due penalty. This organization differs from one social realm to another for many reasons, 
Nile Valley Journal of Human studies and social research

including: the relationship between direct interactive structure and the institutional structure; the magnitude of the tunnel structure; and the other established factors of change such as the environmental context, the available resources, the type of the political system, the nature of economic activity, the prevailing culture and the counter culture, the dominant civilizational, the ethnic identities, religion and popular beliefs, shared history, political and class conflicts, etc. These and other factors arrange the system of structural rules within each realm in a specific order, which may, in some cases, be like the order of rules in other realms, but it most cases it is different or contradicted.

Micro realms, for example, tend to arrange the system of rules differently from other realms. In this realm, the direct interactive structure increases, and the focus here is on some vital rules such as regulating basic needs for survival of the individual and organizing instincts of reproduction. However, rules that organize survival of the group recede especially in situations of relative deprivation that affects individuals within this level, as a result of injustice and inequality in the distribution of power and wealth at the community level. In the field of intellectual rules, micro realms tend to focus on the rules of interaction such as solidarity and love, with the decline of rules of exploration and Arts appreciation. In the field of spiritual rules, micro realms tend to be guided by the spiritual rules of religious origin, whereas spiritual rules of philosophical origin recede, and so on.

Taking into consideration that micro realms, in an African society for example, do not arrange their rules 
system as those in a European society. For example, a married lady of who suffers late pregnancy in a rural African society may have a supernatural vision related to the system of structural rules of her realm such as magic or bless seeking. However, the same women in a European rural society may have a logical vision by seeking the help of the doctor. Here appears the significance of the sociological research (anthropological) owing to its tools in measuring the relative weight of structural rules in each of the realms with its correspondent ones along the realm.

However, the system of structural rules in the meso realm is different from micro social realm. The relation between direct interactive structure and the hierarchical institutional structure is balanced. In the system of dynamic rules, the focus is given to organizing the survival of local groups or the social institution, while other dynamic rules recede especially in the case of the existence of non-integrated ethnic group in the larger community, which generates tension and conflict between the two groups. In the field of intellectual rules, the focus is given to exploration and arts appreciation which strengthen the local community or institution's identity. In the field of spiritual rules, ethics of philosophical origin integrate with rules of religious origin.

While, in the macro realm, we find that the system of structural rules achieves the public interests of all citizens across the hierarchical institutional structure in ideal conditions. This structure may be influenced as we mentioned by abusive authoritarian or weird agencies, so it is organized in such a way as to preserve the interests of the dominant political and economic elite. The structural rules within this realm are organized in a way that faces challenges, conflicts and risks that the realm may suffer 
Conflicted Rules Theory (CRT)

A New Arab Theory in Sociology

Dr. Ahmed Mousa Badawi

Nile Valley Journal of Human studies and social research

through the dark tunnel structure and its horizontal and vertical network of relationships with the region realm and global society realm. There is evidence of the fact that semi-permanent conflict governs the relationship between different social realms or between structural rules systems in these realms.

We may take an example of the coexistence, integrative and conflicted relations that connect between structural rules of the five social realms, and how the change of the structural rule leads to integration here, coexistence and conflict there. The example is about the structural rules governing sexual practices within different social realms, and how change occurs in these rules. We will just focus on homosexuality. It is known, as studies suggest, that this phenomenon is old, however, it remained always limited and secret till there appeared a qualitative change in the rules which can be illustrated in the following points:

(1) Structural Rules at the Level of Micro-Sociology:

homosexuality contradicts the active rule related to the instinct of procreation, as it also contradicts the spiritual rule which prohibits this practice and the legal rule based on these two rules: the dynamic and the spiritual. All micro realms agree on this, whether they believe in heavenly religions or man-made ones, and whether they are urban, rural or desert realms. Everyone considers that Heterosexual relation the only socially accepted sexual practice. Regardless of individual deviations in this regard, most societies knew secret groups that applied contrary rules on homosexuality within the dark tunnel structure. 
Nile Valley Journal of Human studies and social research

(ISSN : 2536 - 9555)

\section{(2) Change in structural rules in meso realm:}

With the increase of individualism as a way of life in Western societies, the homosexual groups came out of the dark tunnel and through the active agency and called for one's right in practicing pure love, without compliance with the direct interactive or institutional rules governing sexual relationships. The active agency succeeded in changing rules governing sexual practice in 1967, when Britain made an amendment in laws, allowing homosexuality as an acceptable social agency as long as it is practiced between two rationale adults who accept the practice. Changing of legal rule in Britain means the recede of the dynamic and spiritual rules to the margin of the rule order, and the focus now is given to intellectual rules associated with freedom and amusement.

In spite of this change, the micro and meso realms in Britain and other Western societies, according to recent studies, still retain to this moment the old rule that moved now from the institutional stage into the direct interactive structure. The rule is now being reproduced through the spontaneous process of socialization by the family using customary moral sanction authority, while avoiding the use of physical penalty against homosexuals, so as not to fall under the law. This is what we call structural realty, which appears when the political system imposes a new rule.

It is a state of semi-conflicted coexistence between the old and new rules. The semi-conflict nature here occurs due to two reasons: (1) That the new institutional rule is itself the counter-rule that governed homosexuality in the dark tunnel structure, removed the old to the common interactive structure, and did not negate it totally from existence. They coexisted together despite their total 
contradiction. (2) The new institutional rule is part of a package of other rules that regulate sexual behavior, are not inconsistent with common interactive rules, and guarantee protection against sexual assaults. For example, in European schools, codes of conduct are strict in protecting children from sexual harassment, so that even teachers are not allowed access with kids to health facilities or changing places. As well as that it prevents touching the child only within reasonable limits such as shaking hands or touching the head, and other similar rules.

(3) Change of structural rules in the region realm and the global society realm:

After the change of the rules organizing homosexuality in Britain, the power of the active agency of homosexuality groups has increased in different areas of Western societies. Thus, the homosexuality gained ground in Scotland, Northern Ireland and New Zealand. Then it went out from scope of the European territory to Canada and the United States. The list of countries confessing homosexuality is on rise. While some countries like Norway, the Netherlands, Belgium, Spain, Canada, and some states in the US have gone beyond enacting laws protecting homosexuality as they took a greater step as to grant the right of documenting marriage between homosexuals, which means the total social institutionalization of homosexual rights, to be part of the social system In these countries.

A great global debate took place on this shift and it ended in favor of the new structural rules organizing the homosexual practice. As a result, major mental health 
Nile Valley Journal of Human studies and social research

(ISSN : 2536 - 9555)

organizations around the world cancelled the classification of homosexuality as a psychological disorder including World Health Organization in 1990.

(4) Structural Rules Organizing Sexual Practice in Arab Society:

Across Arabic and Islamic societies with their various social realms, we find that the system of rules organizing sexual practices within the interactive structure or within the institutional structure integrate together to adhere to the standards of human continuity as an active rule and prohibit homosexuality as a religious rule, and apply penalty to homosexuals as a legal rule. This system of rules completely contradicts the system of rules organizing sexual practice that the global realm institutions try to force upon other social realms. Through this example and others, the nature of conflicted relations among the systems of structural rules in the five social realms can be revealed. This also reveals the extent of contradiction and difference between the Arab and Islamic world's vision in the various social realms on one hand, and the Western World's vision in the region and global levels on the other hand.

Thus, we assume that each one of the five social realms keeps a special order of the system of structural rules, which makes it respond to the factors of change in a different way from other realms. Because these realms are overlapping and interactive, it happens sometimes that a process of settlement of the difference is made through the relationships of temporary coexistence, or partial integration between rules. However, in most cases the difference is out of settlement, a matter that creates conflicts in life and within social practices. 
Conflicted Rules Theory (CRT)

A New Arab Theory in Sociology

Dr. Ahmed Mousa Badawi

Nile Valley Journal of Human studies and social research

Generally speaking, the Arab sociology is required to study possible positive or negative impacts of change resulting from the dominance of Out-realms (region and global realms). The change imposed from these two levels often leads to an incompatibility or refusal from In-realms, a matter that creates anti-changing mechanisms that produces intended and unintended effects in the social structure, which need sociological research to trace these effects and to identify its immediate causes.

In this article, I have attempted to present a general outline of (CRT), and in future studies I will try to test their explanatory power through field research. As it is the first full-fledged sociological Arab theory, it demonstrates the ability of Arab researchers to emerge from the state of scientific dependency and contribute seriously to develop sociology of Out and In- realms. I hope that the theory will be subject to serious discussion in criticism, and to be a starting point towards a different Arab sociology.

\section{References;}

1- Alexander Jeffery. C. 1988. Parsons' structure in American Sociology. Sociological Theory. 6 (1): 96-102.

2- Alexander, Jeffrey C. 1989. Structure and meaning: relinking classical sociology. New York: Columbia University Press.

3- Archer, Margaret S. 1995. Realist social theory The morphogenetic approach. Cambridge: Cambridge University Press.

4- Archer, Margaret Scotford. 2000. Being Human: The Problem of Agency. Cambridge, U.K; New York: Cambridge University Press.

5- Badawi, A. M. (2004). the state of knowledge of Egyptians youth. Unpublished Master Thesis, Faculty of Arts - Ain Shams University. 
Nile Valley Journal of Human studies and social research

$$
\text { (ISSN : } 2536 \text { - 9555) }
$$

6- Badawi, A. M. (2009) Social Dimensions of Knowledge Product and Obtainment: The Case of Sociology in Egyptian Universities. Beirut: Centre for Arab Unity Studies. (Arabic)

7- Badawi, A. M. (2009), between agency and structure - research in the theory of practice according to Pierre Bourdieu, Idafata (the Arab Journal of Sociology, 8 (4): 9-23. (Arabic)

8- Badawi, A. M. (2013), Middle class transformations in the Arab World. Beirut: Centre for Arab Unity Studies. (Arabic)

9- Badawi, A. M. (2014), The poor perceptions of the Egyptian revolution Sociological research on the causes, objectives and results of the 25 January revolution, unpublished paper, as part of the international meeting of Arab sociologists before the questions of current transformations held at the National Center for Research in Social and Cultural Anthropology 18-20 February 2014 (Oran, Algeria).

10-Beck, Ulrich 2013, Global Risk Community: In Search of Lost Safety, translation by Ola Adel, Hind Ibrahim, Bassent Hassan, Cairo, National Center for Translation

11-Beck, Ulrich. 1989. "On The Way To The Industrial Risk-Society? Outline Of An Argument". Thesis Eleven. 23 (1): 86-103.

12-Beck, Ulrich. 2002. "The Cosmopolitan Society and its Enemies". Theory, Culture and Society. 19 (1/2): 17-44.

13-Beck, Ulrich. 2016. "Varieties of Second Modernity and the Cosmopolitan Vision". Theory, Culture \& Society. 33 (7-8): 257270.

14- Bourdieu, Pierre, and C. Dr.. Vakunt. 1997. Sociology questions in reflexive sociology, Translated by Abdel-Jalil El-Kor, Casablanca: Dar Toubkal.

15- Bourdieu, Pierre. 1977. Outline of a theory of Practice. Translated 
Conflicted Rules Theory (CRT)

A New Arab Theory in Sociology

Dr. Ahmed Mousa Badawi

Nile Valley Journal of Human studies and social research

by Richard Nice, Cambridge: Cambridge University Press.

16-Bourdieu, Pierre. 1993. The Field of cultural production: essays on art and literature. Cambridge: Columbia University Press..

17- Bourdieu, Pierre. 1994. Symbolic violence: research in the origins of educational sociology. Translated by Ndeer Jahel. Beirut; Casablanca: Arab Cultural Centre.

18- Collins, Randall. 1975. Conflict Sociology: Toward an Explanatory Science. New York: Academic Press.

19-Collins, Randall. 1979. The Credential Society. New York: Academic Press.

20-Giddens, Anthony 1987, Social Theory and Modern Sociology, Stanford, Stanford Uni. Press

21-Giddens, Anthony. 1984. The constitution of society: outline of the theory of structuration. Cambridge: Polity Press

22-Giddens, Anthony.(2005). Sociology. Translated by, Fayez El Sayagh, Beirut: Centre for Arab Unity Studies. (Arabic)

23-Stryker, S. (1980). Symbolic interactionism: A social structural version. Menlo Park, Calif: Benjamin/Cummings Publ. Co.

24-Stryker, Sheldon. 1987. "The Vitalization of Symbolic Interactionism". Social Psychology Quarterly. 50 (1): 83-94. 